\title{
The Impact of Environmental Turbulence on Product Innovation in Small to Medium Enterprises in
} Harare, Zimbabwe

\author{
Caroline Zimuto ${ }^{1}$, Maxwell Sandada ${ }^{1}$, Tinashe Chuchu ${ }^{2}$, Tinashe Ndoro ${ }^{2}$ \\ ${ }^{1}$ Graduate School of Management, University of Zimbabwe \\ ${ }^{2}$ Marketing Management Department, University of Pretoria, South Africa \\ tinashe.chuchu@up.ac.za
}

\begin{abstract}
The purpose of the research was to examine the impact of environmental turbulence on product innovations in small to medium enterprises (SMEs). In the study environmental turbulence consisted of five dimensions namely, supplier turbulence, technological turbulence, market turbulence, regulatory turbulence and competitive intensity. A cross-sectional quantitative research design was adopted in the study. The study sample was drawn from a pool of 3,000 SMEs both unregistered and registered with the Ministry of Small and Medium Enterprises in Harare, Zimbabwe. In the study, a total of 200 completed surveys were obtained and analysed. To analyse the research data SPSS23 was utilised. Regression analysis was carried out to establish the cause-and-effect relationship between the independent and dependent variables in the study. The findings of the study showed that technology turbulence and competitive intensity had a statistically significant positive impact on product innovation. Market turbulence was noted as having a statistically significant negative impact on product innovativeness. The main implications established in the study were that SMEs should introduce mechanisms to manage and mitigate market, supplier and regulatory turbulence to ensure that their levels of product innovativeness remain positive.
\end{abstract}

Keywords: Environmental turbulence, product innovation, SMEs, Zimbabwe

\section{Introduction}

The business environment that firms operate in now is characterized by dynamism, hyper-competition and high uncertainty; therefore, for SMEs to remain competitive and be successful they need to be innovative and always adaptive to the market changes. The ability of the firm to introduce new products and services as well as adding value to the existing ones are the essentials for economic growth and development and driving force for the competitive scuffle in the prevailing VUCA environment. If SMEs invest in innovation behaviour, it strengthens their knowledge which leads to organizational resilience that improves firm competitiveness as well as achievement of performance goals. For SMEs to encourage internal innovation in their organizations they need to promote the mindset of looking outside the box in order for opportunities to collaborate. This can be done through knowledge sharing, brainstorming ideas and expanding firm networks which can improve their growth prospects. This mindset is vital for Zimbabwe's large volume of SMEs which are continuously struggling to survive and grow. These SMEs need to grasp the implications of innovation as a real driver of success and competitiveness. Almost all SMEs in Zimbabwe are struggling due to the everchanging business environment and little research has been done in Zimbabwe on how this environmental turbulence affects SME innovation focusing mainly on product innovation.

The studies that have been done in the innovation field, Masevo (2015) and Chiwara (2015) tried to investigate environmental factors that influence innovative ideas and activities and the effect of various environmental turbulence dimensions on SME innovativeness lacks similar attention. It is therefore, the purpose of this study is to fill this gap in the literature and examine how environmental turbulence affects product innovation in Zimbabwean SMEs. In all countries around the world SMEs have become prominent in terms of employment creation and contribution to Gross Domestic Product but their full potential remains untapped. These small firms aid in revenue generation and they create communal strength. They provide large enterprises with local supplies and services and communities can access products and services at low and affordable costs. In most African countries SMEs represent a significant proportion of the business sector and they provide more than $50 \%$ of the jobs and contribute a sizeable percentage of GDP. They take close to $85 \%$ of employment in the productive sector in Ghana and $70 \%$ of the Ghanaian business. In South Africa and Egypt, SMEs constitute 91\% of formal businesses (Abor \& Quartey, 2010). Therefore, this creates a gap in terms of studying how the turbulent environment influences SME innovation for them to survive and grow. 
Context of the Study: The business environment is changing rapidly giving organizations challenges to stay in the market and innovativeness has become the pillar for business survival and competitive advantage. The turbulent environment is the main driver for SME innovativeness and it forces firms to respond by innovating in order to survive (Uzkurt, Kumar, Kizman \& Sert, 2012). SMEs must reconfigure their capabilities with increasing competition, changing technology, markets and regulations to catch up with the customer needs. According to Hutt and Speh (2010) organizations are required to continuously innovate, their products and processes in turbulent environments in order to outstand stiff market competition. Many SMEs with great business ideas fail if they are reluctant and fail to adapt to the changes in the business environment. In Zimbabwe, indigenization policy has sensitized skilled and experienced people to abandon their jobs to search for better livelihoods and this led to an increase of SMEs competing for the same declining customer base. Mbizi, Hove, Thondhlana and Kakava (2013) postulate that SME sector in Zimbabwe is not growing as fast as it should be to create employment and significantly contribute to the economy's GDP because most of them are failing to beat the competition. This means that for SMEs to survival they should make themselves unique by continuously innovating their products and business processes.

Purpose of the Study: The purpose of the current study is to investigate the impact of the dimensions of environmental turbulence (namely, technological, market, regulatory, supplier and competitive intensity) on product innovativeness by SMEs operating in Zimbabwe. Environmental turbulence is noted as a significant predictor in the levels of innovativeness by firms (Uzkurt et al., 2012). SMEs experience a plethora of challenges as they operate in the business environment and the turbulence of various environmental factors can have either positive or negative effects on the levels of product innovativeness by the SMEs (Kyrgidou et al., 2013). It can be noted that the levels of product innovativeness by SMEs in developing and developed countries are different due to the differences in environmental challenges these firms experience (Uzkurt et al., 2012). The objective of this study is on the impact of environmental turbulence on product innovativeness of SMEs operating in the turbulent business environment in Zimbabwe. In order to achieve the research objectives of the study, the following research questions were proposed: What is the influence of environmental turbulence on product innovations by SMEs operating in Zimbabwe?

\section{To Aid in Answering the Main Research Question, the Following Sub Questions Were Proposed}

- What is the impact of supplier turbulence on product innovations in SMEs?

- What is the impact of technological turbulence on product innovations in SMEs?

- What is the impact of market turbulence on product innovations in SMEs?

- What is the impact of regulatory turbulence on product innovations in SMEs?

- What is the impact of competitive intensity on product innovation in SMEs?

\section{Literature Review}

In the present study literature on small businesses and environmental turbulences will be discussed. The literature review section will commence by providing a discussion of SMEs followed by a discussion of environmental turbulence.

Small and Medium Enterprises (SMEs): There is no single and standard generally accepted the definition of SMEs since it differs from country to country and also between reporting entities. Individuals and organizations identify SMEs differently in such a way that an enterprise regarded as small and medium in one country is viewed in a different way in another. Mbizi et al. (2013) are of the view that SMEs have no globally agreed definition and suggests that SMEs can have many definitions even in a single jurisdiction depending on the type industry they operate in. According to Dragnić (2014) some of the common indicators used in defining SMEs are a number of employees, capital assets, turnover levels type of industry and ownership of the enterprise. Abor and Quartey (2010), suggest that SMEs can be defined in terms of the production method and legal status. Many countries define the SME sector as a group which comprises of the self-employed and the "micro" enterprises with employees less than 10.

Importance of SMEs to the Economy: In the Zimbabwean context SMEs contribute positively towards job creation and economic growth (Chiwara, 2015). SMEs are key drivers of wealth creation and economic 
development through high levels of innovativeness. In this respect, SMEs lower the levels of unemployment and poverty. SMES promote income distribution and the uplift of communities. SMEs play a vital role in all economies and they have become the engines for economic growth and development of many countries in the world and Zimbabwe is no exception. In his study Johari (2012) argued that the role of SMEs in developing countries has been increasing due to the high rates of unemployment and he went on to say the only way for these developing countries to overcome the challenges of poverty and unemployment is to encourage growth and development of SMEs.

Challenges Faced by SMEs in Embracing Innovation: Innovation generally requires organisations to transform knowledge capital to innovation outputs, such as new and improved quality products or processes, organisational or marketing changes (Pratono, 2014). Therefore, SMEs need to invest in knowledge capital to ensure that they increase their innovation capabilities. Furthermore, innovation is enhanced by factors such as, human capital, organisational capital, technology, physical production facilities and equipment (Pratono, 2014; Okey, 2014). These innovation factors require the organisation to perform specific innovation activities depending on the technical sophistication of the introduced innovations.

Environmental Turbulence: For organisations to succeed and sustain a competitive advantage they need to assess the external environment and adopt appropriate responses within the environment. Contemporary organisations operate in an environment which is characterised by dynamism, uncertainty and turbulence which greatly affects business activities (Baba, Mahmood \& Halipah, 2017). In this vein, environmental turbulence is defined by Suddaby (2010) as the continuous changes in environmental factors which influence the performance and operations of firms. Environmental factors (such as, technology, market changes, regulations, suppliers and competitive intensity) influence the level of product innovativeness by SMEs (Chiwara, 2015; Masevo, 2014; Okey, 2014; Uzkurt et al., 2012). From the aforementioned assertions the proposed conceptual framework and hypothesis for the study were developed.

\section{Figure 1: Conceptual Model}

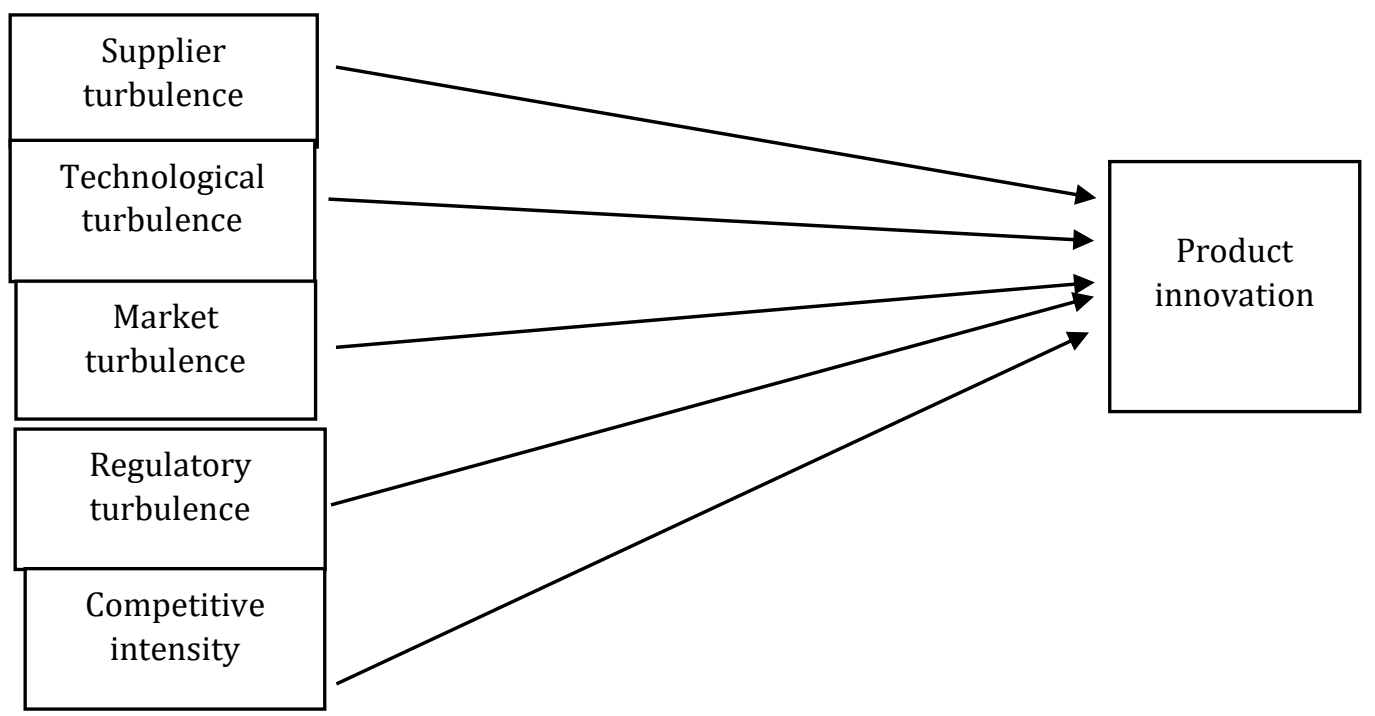

Source: Author

\section{Hypotheses}

\section{Hypothesis 1:}

Supplier turbulence has a significant positive impact on product innovation.

\section{Hypothesis 2:}

Technological turbulence has a significant positive impact on product innovation.

\section{Hypothesis 3:}

Market turbulence has a significant positive impact on product innovation. 


\section{Hypothesis 4:}

Regulatory turbulence has a significant positive impact on product innovation. Hypothesis 5:

Competitive intensity has a significant positive impact on product innovation.

\section{Methodology}

Research Approach: The study adopted a cross-sectional quantitative research design. Data was collected from a questionnaire that was adapted from previous empirical studies, namely, Uzkurt et al. (2012); Pratono (2014); Okey (2014); Masevo (2015) and Chiwara (2015). The study sample was drawn from a pool of SMEs both unregistered and registered with the Ministry of Small and Medium Enterprises in Harare, Zimbabwe. The population comprised of approximately 3,000 SMEs from different industries in the SME sector. From this population, through random sampling a total of 200 completed questionnaires were obtained. Moreover, the researcher was guided by the formula developed by Yamane in 1967 to determining the sample size of the study. Yamane's methods indicate that a $\pm 5 \%$ accuracy level and a $95 \%$ confidence level should be accepted for study.

Descriptive Statistical Analysis: Descriptive statistics in the form of frequency distributions and percentages were used by the researcher to describe the demographics of the respondents such as gender, age, level of education, position in the company, number of employees, sector of operation, number of years the company has been in business and annual sales revenue.

Normality Test: The researcher performed the test for normality to establish how the data was distributed before analysing the data. The normality test which was adopted by the researcher was the Shapiro - Wilk test which is used for sample sizes less than 2000. Shapiro - Wilk test with a "p" value greater than 0.05 ( $p$ > 0.05 ) indicates that data is evenly distributed meaning that the selected sample does not significantly vary from the study population hence, the parametric tests can then be performed using the data. If the " $p$ " value is less than $0.05(\mathrm{p}<0.05)$, it means that data is not normally distributed suggesting that the sample significantly differs from the study population therefore, the non-parametric tests are then adopted. For the study the " $p$ " value was less than 0.05 which indicates that the data was not normally distributed, hence non-parametric tests were performed.

Correlation Analysis: The correlation analysis was performed to establish the degree of association between the independent and the dependent variables. The Spearman correlation was computed since it is a nonparametric test which applies to data which is not normally distributed. The analysis performed involved examining the relationship of each independent variable (technological turbulence, regulatory turbulence, supplier turbulence, market turbulence and competitive intensity) with the dependent variable (product innovation). In the analysis the researcher focused on four aspects which included direction, magnitude, significance and multicollinearity. Correlation of variables ranges from - 1 for a perfectly negative relationship to $\mathrm{a}+1$ for a perfectly positive relationship, whilst 0 shows that no relationship exists. For a significant correlation to exist between variables, significance levels should be less than 0.05 . Multicollinearity tests whether the independent variables are independent of each other. If VIF is greater than 10 it means there is multicollinearity. The results of the analysis indicated a low degree of multicollinearity between 1 and 1.2, which indicated that there was no correlation between the independent variables.

Regression Analysis: After establishing that there was no multicollinearity between the independent variables, a multiple regression was performed. Multiple regression analysis was performed to establish the cause-and-effect relationship between the independent and dependent variables in the study.

Validity and Reliability: For the instrument to be reliable the Cronbach's Alpha score should be at least 0.70 . In the study, the overall Cronbach's alpha score for the research instrument was 0.78. This meant that the reliability of the instrument was acceptable. 


\section{Results}

Descriptive Statistics: The section below presents the response rates and the demographic characteristics of the respondents and SMEs.

Response Rate: The researcher sent online and self-administered survey questionnaires to a random sample of SMEs in Harare. A total of 353 survey questionnaires were distributed to firms that were identified as SMEs. From the total distributed questionnaires, 200 usable questionnaires were returned and captured. In this respect, a response rate of $56.7 \%$ was achieved.

Gender: From the survey, $61 \%$ of respondents were males and 39\% were females. This implies that SMEs in Harare are mostly operated and owned by males. Nonetheless, it is evident that females also operate the SMEs in Harare.

Age: The participants of the study were predominately within the age group, 21-34 years (38.5\%) and 35-44 years $(30 \%)$. The lowest number of participants came from the age group of $45-54$ years with $(8.5 \%)$ followed by the 21 and below age group with (9.5\%). The age group 55 years and above represented (13.5\%) of the participants.

Educational Level: In the study, 6.5\% of respondents attained secondary education, $9.5 \%$ had certificates, $33 \%$ had diplomas, $45.5 \%$ had bachelor's degrees and 5.5\% had master's qualifications. No respondents indicated that their highest qualification was primary education. The biggest number of respondents had tertiary qualifications, i.e. diploma and above which indicates that SME operators in Zimbabwe have high education levels.

Number of Employees: In the study, $43.5 \%$ of SMEs had 50 and below employees, $44.5 \%$ had $51-100$ employees and $12 \%$ had more than 100 employees.

Period of Operation: The majority of SMEs (38\%) had been in operation for 1-5 years, 33\% of the SMEs for 6-10 years and $17.5 \%$ had been operating for $11-20$ years. Only $11.5 \%$ had been operating for more than 21 years.

Tests of Relationships: To test the relationships between the independent variables (market turbulence, regulatory turbulence, technological turbulence, supplier turbulence and competitive intensity) and the dependent variable (product innovation), the study employed a multiple regression analysis. The regression equation generated in the study is presented below: Product innovation $=2.722+0.481 \mathrm{CI}+0.147 \mathrm{TT}-\mathrm{MT} 219$, from the regression equation the constant of 2.722 indicates that when environmental turbulence is zero product innovation is 2.722 . TT is technological turbulence and CI is competitive intensity. As shown by the equation, an increase in competitive intensity by one unit results in 0.481 -unit increase in product innovation and an increase in technological turbulence by one unit results in 0.147 units increase in product innovation. On the other hand, an increase in market turbulence by one unit results in a decrease in product innovation by 0.219 units. 
Table 1: The Overall Findings from the Multiple Regression Analysis are presented in table below Coefficients $^{\mathrm{s}}$

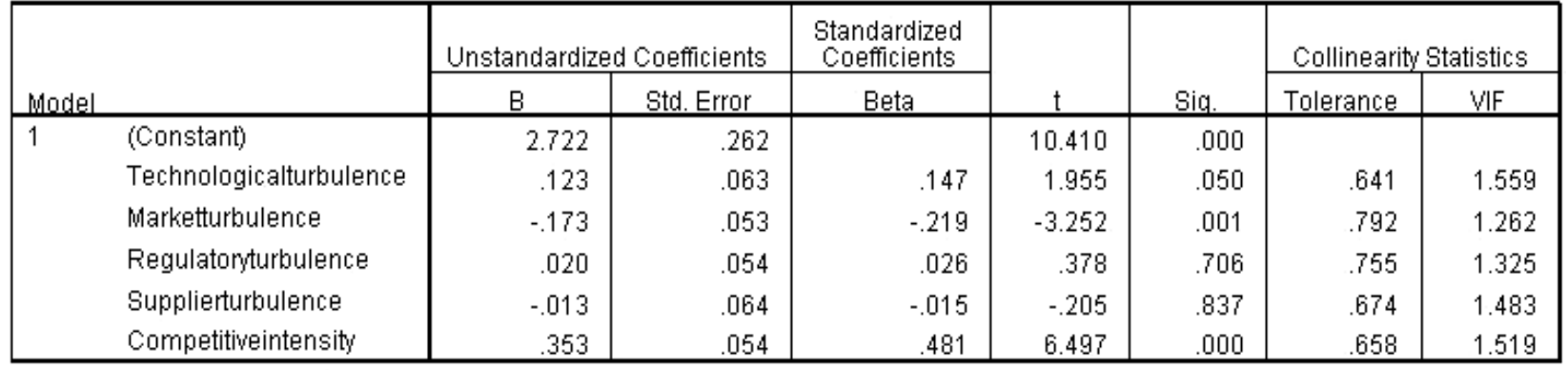

a. Dependent Variable: Productinnovation

Source: Primary data

Hypotheses testing and Discussion: The results revealed a mixed positive and negative effect of environmental turbulence on SME innovativeness. As shown by the results, several dimensions of environmental turbulence significantly impact product innovation. This is in line with the research done of Uzkurt et al. (2012) which indicates that environmental uncertainties positively impact innovativeness. Similarly, the research conducted by Droge et al. (2008) also supports the findings of the study, as their findings indicated that product innovativeness increases during periods of environmental uncertainty. Rhee, Park and Lee (2010) found that SMEs seek to improve their business performance during turbulent times by introducing new product innovations. The first hypothesis $(\mathrm{H} 1)$ of the study was not accepted $(\beta=-0.015 ; \mathrm{p}=$ 0.837). Thereby implying that supplier turbulence did not has a statistically significant impact on product innovation. In this vein, it can deduce that supplier uncertainty does not affect a firm's innovativeness.

The second hypothesis (H2) in the study was accepted ( $\beta=0.147 ; \mathrm{p}=0.05)$. Implying that technological turbulence has a positive statistically significant impact on product innovativeness. These findings are in line with the findings by who found that in conditions of high technological turbulence SMEs tend to be responsive by developing new combinations through innovativeness. On the other hand, the third hypothesis (H3) was not accepted $(\beta=-0.219 ; p=0.001)$ in the study and it was noted that market turbulence had a statistically significant negative impact on product innovativeness. This finding in the study is in line with the findings by Abdallah and Person (2014) who studied SMEs in the Swedish market and found that market uncertainty had a negative impact on innovativeness. On the other hand, Uzkurt et al. (2012) conducted a study in a Turkish market and found that both technological and market turbulence had a positive impact on innovativeness in SMEs. Moreover, in the study by Uzkurt et al. (2012), it was noted that market turbulence had a more significant impact on innovation than technological turbulence. However, in this study the results indicate that SMEs experience higher levels of innovation during conditions of technological turbulence and lower levels of innovation in conditions of market uncertainty. These results indicate that Zimbabwean and Turkish markets are different hence SMEs in different countries behave differently when faced with environmental turbulence.

The fourth hypothesis ( $\mathrm{H} 4)$ of the study stated that regulatory turbulence had a significant positive impact on product innovation in SMEs. From the regression analysis it was noted that regulatory turbulence had no statistically significant impact on product innovation $(\beta=0.026 ; p=0.706)$. In this respect, $(H 4)$ was rejected in the study. These findings are in contrast with the results of the study by in which it was found that regulations positively impact on SMEs innovativeness. The last hypothesis (H5) indicated that competitive intensity had a significant positive impact on product innovation. From the regression analysis it was found that competitive intensity had a statistically significant positive impact on product innovativeness $(\beta=0.481$; $\mathrm{p}=0.000$ ). Moreover, it was found that competitive intensity had the greatest impact on product innovativeness. In this respect, it can be argued that SMEs operating in competitive markets tend to be more innovative, not only due to pressures from competitors but also through the knowledge achieved from observing the innovative products produced by their competitors (Hahn, 2010). These findings of the study are in line with the findings by Kyrgidou et al. (2013) and Didonet et al. (2012) who investigated the relationship between firm performance and innovation and found that firm innovativeness ranked high in 
competitive environments because firms wanted to achieve a higher competitive advantage. Similarly, Gabsi, M'henni and Koouba (2008) studied SMEs in Uzbekistan and China and the results revealed that competitive intensity is a powerful positive predictor of SME innovativeness.

Managerial Implications: It can be noted that environmental uncertainty results in innovation which influences business success and performance. The findings of this study indicate that competitive intensity and technological turbulence are key drivers of product innovation in SMEs. If SMEs are operating in competitive markets, they need to innovates their products and make them unique in order to gain a competitive advantage and survive. If technology in the industry keeps changing, SMEs need to develop new products and advance them to keep up with the changing technology so that they do not lose their market share to competitors. SMEs should therefore, invest more resources in product innovation when competition in the industry is high and when technology is changing in order to succeed and survive in the market. Supplier and regulatory turbulence are noted as having no significant impact on product innovation. The findings of the study can be used by SMEs to differentiate themselves in their respective industry marketplaces.

To remain superior and achieve high performance, SMEs should seek to increase their levels of innovation by managing environmental turbulence dimensions. In Zimbabwe, the government needs to develop policies that support innovation by SMEs in order to ensure that SMEs positively contribute to the economy. Moreover, the Zimbabwean government should provide regulations that create a conducive, environment for SMEs to innovate with specific attention given to technological turbulence, market turbulence and competitive intensity. In this respect, for SMEs to succeed during technological turbulence they need to improve the perceptions by consumers that the new technology introduced offers benefits that are not present in the existing technology. This can be achieved by communicating the new product benefits to potential customers through promotions, product demonstrations and personal selling. When implementing product innovations, SMEs should extensively research potential customer's needs in order to develop sound products that will allow them to gain a competitive advantage.

\section{Conclusion}

Innovativeness has become the key strategy for businesses to successfully compete in the market. Organisations are adopting innovations in order to increase business performance and outperform competitors during conditions of environmental turbulence. In this respect, it was important to study how environmental turbulence affects product innovativeness. The present study focused on investigating technological, market, regulatory, supplier and competitive intensity uncertainties that affect product innovations in SMEs in Zimbabwe. The results of the analysis showed that several dimensions of environmental turbulence (technological, market and competitive intensity) have an impact on product innovativeness by SMEs. Technological turbulence and competitive intensity were noted as having a statistically significant positive impact on product innovativeness, hence the greater the level of technological turbulence and competitive intensity the greater the product innovativeness by SMEs. On the other hand, the greater the market turbulence the lower the level of product innovativeness by the SMEs in Zimbabwe. Hence, SMEs should respond to market uncertainty using varying survival tactics such as, marketing tactics, price wars and or increase customer relationship management.

Suggestions for Future Research: Future research can be in the form of longitudinal studies in which the effect of environmental turbulence on product innovativeness is investigated over an extended period of time. Furthermore, future research can involve investigating additional factors that influence product innovation such as, the industry in which the SMEs exists. A limitation of the study was that only SMEs in one city (Harare) were utilised for the study and this could have influenced the results of the study. Future studies can include more cities and towns in Zimbabwe to ensure that the results are more generalisable. Future research can investigate the influence of demographic variables such as the age, gender and ethnicity of the owners and managers of SMEs in influencing product innovativeness in different environmental conditions. 


\section{References}

Abdallah, L. \& Person, M. (2014). The effects of environmental uncertainty conditions on organizational innovativeness and performance of SMEs. Blekinge Institute of Technology School of Management. (Master's dissertation)

Abor, J. \& Quartey, P. (2010). Issues in SME development in Ghana and South Africa. International Research Journal of Finance and Economics, 39(6), 215-228.

Baba, M., Mahmood, R. \& Halipah, A. (2017). The moderating role of environmental turbulence on the relationship between organizational learning and firm innovativeness. International Journal of Management Research and Reviews, 7(2), 148-159

Chiwara, O. M. (2015). An Evaluation of the Factors Affecting Growth of SMEs in Zimbabwe: A Case Study of SMEs in Harare. University of Zimbabwe (Master's dissertation)

Didonet, S., Simmons, G., Díaz-Villavicencio, G. \& Palmer, M. (2012). The relationship between small business market orientation and environmental uncertainty. Marketing Intelligence \& Planning, 30(7), 757779.

Dragnić, D. (2014). Impact of internal and external factors on the performance of fast-growing small and medium businesses. Management: Journal of contemporary management issues, 19(1), 119-159.

Droge, C., Calantone, R. \& Harmancioglu, N. (2008). New product success: Is it really controllable by managers in highly turbulent environments? Journal of Product Innovation Management, 25(3), 272-286.

Gabsi, F., M'henni, H. \& Koouba, K. (2008). Innovation determinants in emerging countries: an empirical study at the Tunisian firms level. International Journal of Technological Learning, Innovation and Development, 3(3), 1-23

Hahn, S. (2010). Competition, comparison, and innovation. Economics Letters, 106(2), 122-124.

Hutt, M. D. \& Speh, T. W. (2010). Business marketing management: B2B.10 ${ }^{\text {th }}$ Edition, Cengage Learning, Canada.

Johari, H. (2012). The role of small and medium enterprises (SMEs) in the country's economic development. Journal of Basic and Applied Scientific Research, 2(10), 10279-10287.

Kyrgidou, L. P. \& Spyropoulou, S. (2013). Drivers and performance outcomes of innovativeness: An empirical study. British Journal of Management, 24(3), 281-298.

Masevo, B. (2015). Factors that influence innovation in the Paint manufacturing industry in Zimbabwe. A case of Solid Paints Company in Harare. Solusi University.

Mbizi, R., Hove, L., Thondhlana, A. \& Kakava, N. (2013). Innovation in SMEs: A review of its role to organisational performance and SMEs operations sustainability. Interdisciplinary Journal of Contemporary Research in Business, 4(11), 370-389.

Pratono, A. H. \& Mahmood, R. (2014). Social Capital and Firm Performance: Moderating Effect of Environmental Turbulence. Asian Social Science, 10(19), 59-68.

Rhee, J., Park, T. \& Lee, D. H. (2010). Drivers of innovativeness and performance for innovative SMEs in South Korea: Mediation of learning orientation. Technovation, 30(1), 65-75.

Uzkurt, C., Kumar, R., Kizman, H. \& Sert, H. (2012). The impact of environmental uncertainty dimensions on organisational innovativeness: An empirical study on SMEs. International Journal of Innovation Management, 16(2), 1-23.

Suddaby, R. (2010). Challenges for institutional theory. Journal of Management Inquiry, 19(1), 14-20. 